\title{
Type studies on Agaricales described as Clitocybe and Omphalina
}

\author{
Harri Harmaja \\ Department of Botany, University of Helsinki, Helsinki 17, Finland
}

\begin{abstract}
The holotypes or type material of 17 species and one form described as Clitocybe (Fr.) Staude and one species described as Omphalina Quél. have been scrutinized. All but one of the taxon names treated in the study turned out to be synonyms and represent earlier described species of Clitocybe. One species proved to be a valid one, but belongs to Lepista (Fr.) W. G. Smith, so that the new combination Lepista subconnexa (Murr.) Harmaja is made.
\end{abstract}

The present study is a part of the results of the examination of a great number of types or type materials from various parts of the world. The work had to be carried out prior to the publication of my study on the genus Clitocy be in Fennoscandia.

Various synonyms (and names suspected to be such) have been incorporated in handbooks and been widely used in local floras and even monographs. This could have been avoided by studying the types of these often fairly recently described species, and comparing them with sufficiently extensive material of other, older species, in order to find out whether they possibly fall within the normal amplitude of variation of the latter. However, revision of this type is sometimes difficult since instead of the existing type specimen one may be sent other material, or a small fragment of fruit body of the type specimen. For this reason uncertainties still remain regarding the rather frequently used name C. tenuissima Rom. In addition, I could only obtain very small fragments of $C$. costata Kühn. \& Rom. and C. subsericella Rom. (sericella), and was unable to come to any decision in respect of these names (their spores were \pm identical with those of $C$. squa- mulosa and their pileus gave a chestnut brown $\mathrm{KOH}$ reaction, so they may both be very nearly related to $C$. squamulosa, if not identical with this species).

In my treatment of the Fennoscandian Clitocybes (Harmaja 1969; see p. 114) I perhaps did not make it sufficiently clear that, at present, owing to the lack of good protologue and type material, all the species of Fries which he described on the basis of Fennoscandian (i.e., Swedish) material have to be considered nomina dubia (apart from those few, \pm clearly distinguished and/or common species which were considered valid in my study, i.e., very likely to be what Fries meant with them). The true number of species of Clitocybe in southern and central Sweden is much smaller than that reported by FrIEs, even if the different delimitation of the genus is taken into consideration. It is to be hoped that an end may be put to the somewhat nonchalant use in local floras etc. of such names as $C$. brumalis, $C$. cacabus, $C$. mortuosa, C. olorina, C. orbiformis, C. paropsis, C. pausiaca, C.tornata, C.tuba, C.vermicularis and others. If these species cannot be traced and cleared up by studying the Swedish Clitocybe material both in the field 
and in the laboratory, there is even less chance that clarity can be reached in Central Europe or North America, where there is less probability of finding these species and the conditions are less suitable for arriving at a correct interpretation of the vague Friesian descriptions.

The taxonomy and nomenclature of Clitocybe are according to Harmaja 1969.

Acknowledgements. - I am indebted to the staff of various herbaria for placing material at my disposal. Dr. P. Isoviita, Helsinki, kindly discussed with me some intricate nomenclatural questions, and Mrs. Anna A. Damström, M. A., revised the English language.

Clitocybe aberrans Velenovský, Novitates mycologicae, 74. 1939. - Holotype (Cizechoslovakia, Mnichovice 25. VIII. 1936, J. Velenovský; PR 153423) examined. This is very probably the holotype. It belongs to C. candicans. The protologue indicates the spores to be globose, but this discrepancy between the description and the true situation may not necessarily be serious, because on many occasions Velenovský reported the spores to be globose when they surely are not. This situation is met with also later in the present paper.

Clitocybe brunnescens Murrill, Mycologia 5: 208. 1913. - Holotype (U.S.A., Washington, Seattle 20. X.-1. XI. 1911, W. A. Murrill 699; NY) examined. The original description alone suggests $C$. ditopa, and the specimen does indeed represent $C$. ditopa v. ditopa.

Clitocybe compressipes Peck f. autumnalis Kauffman, Pap. Mich. Acad. Sci. Arts Lett. 8: 191. 1928. - Holotype (part) (U.S.A., Michigan, Washtenaw Co., Ann Arbor 23. X. 1926, G. H. Kauffman; MICH) examined. The spores are somewhat longer than is indicated in the protologue. The specimen represents $G$. candicans, which species is not difficult to recognize if the critical macroscopical, sporal and anatomical characters are carefully studied.

Clitocybe fallax Velenovský, Opera bot. čechica 4 (Novitates mycologicae novissimae) : 54. 1947. - Holotype (Czechoslovakia, Mnichovice 19. X. 1941, J. Velenovský; PR 153480') examined. This is obviously the holotype. It is very probably $C$. fragrans, and this determination would agree quite well with the protologue. In Národní Muzeum in Prague there is another specimen of C. fallax (PR 153418) which somebody has designated as »typus», too. However, it does not belong to the type material because it was collected as early as 1935, whereas the protologue of C. fallax only mentions 1941 as the collecting year. This latter specimen belongs to the variable species Collybia dryophila.

Clitocybe gossypina Velenovský, Novitates mycologicae, 76. 1939. - Holotype (Czechoslovakia, Mnichovice X. 1939, J. Velenovský; PR 153398) examined. This is C.candicans once more. Again, there is another specimen in PR designated as »typus» (PR 153474), but it was collected in 1940 and does not belong to the type material. It represents C. candicans, too.

Clitocybe incisa Bigelow, Mycologia 50: 41. 1958. - Holotype (part) (U.S.A., Michigan, Washtenaw Co. 25. V. 1952, H. E. Bigelow 502; MICH) examined. The specimen may have been attacked by a parasite, judging from the external appearance and the scarcity of developed spores. All the diagnostic characters of $C$. sinopica, some ecological and phaenological ones not excluded, are described in the protologue, and the type does indeed represent this species. A paratype (A. H. Smith 18939; MICH), studied by me as well, is likewise C. sinopica. According to my experience of the genus Clitocybe and knowledge of C. sinopica in, say, Sweden, the differences between $C$. incisa and $C$. sinopica as indicated in the protologue surely do not justify the separation of two different species.

It can be mentioned that C. sinopica sensu Bigelow (e.g. 1968) represents a taxon which, though very nearly related, is different from which I suppose FrIes meant with this name. I had already suspected that this was the case (Harmaja 1969: 70), and now that I have studied the specimen H. E. Bigelow 1035 labelled as C. sinopica, I can confirm that this supposition was correct. The collection in question belongs to that short-spored, evidently unnamed taxon. Accordingly, Bigelow was correct in considering that C. incisa and his C. sinopica were different species.

Clitocybe mortaricola Bigelow, Lloydia 31: 48. 1968. - Holotype (part) (U.S.A., Wisconsin, Walworth Co. 28. V.1956, R. L. Shaffer 726; MICiH) examined. Bigelow 
emphasized the diagnostic importance of the pigmented thick-walled hyphae of the epicutis, and also drew attention to the habitat and substrate and to the branched stipe found in one fruit body. He also considered the species to be close to C. gibba. I found the spores somewhat longer than in the original description. There seemed to be some thickish-walled hyphae in the epicutis, though I am not completely sure of this, but I consider the pigmentation to be principally due to the intracellular pigment of the epicuticular hyphae and also to some encrustations. Bigelow thought that the pigment is located in the walls of the thickwalled hyphae and in encrustations. However, the truly diagnostic characters of C. mortaricola (colours, taste, spores, phaenology, and some ecological features) are strongly indicative of C. sinopica, though the mycelial hairs and rhizoids are not mentioned. I cannot approve Bigelow's arguments for treating C. mortaricola, based on one sole collection, as a distinct species. The thickish-walled hyphae are certainly rare in Clitocybe, but the presence of a few of them in the epicutis does not indicate a new species, the occurrence of encrustations is often inconstant in the species of Clitocybe, the dichotomous stipe and habitat in a cellar are surely quite occasional phenomena. As regards the specific name of $C$. mortaricola, as I have pointed out (Harmaja 1969), C. sinopica usually occurs on bare, and sometimes even fertile, soil. I myself once found this species in Finland growing in a mixture of weathered mortar and sand by the ruins of a house (this observation was not included in my thesis). In view of these considerations, I regard C. mortaricola as another synonym of C. sinopica.

Clitocybe murinifolia Murrill, Mycologia 5: 210. 1913. - Holotype (U.S.A., Washington, Seattle 20. X.-1. XI. 1911, W. A. Murrill 300a; NY) examined. The protologue contained no reference to a mealy odour, but this is a beautiful specimen of C. ditopa v. ditopa in agreement with Singer (1942).

Clitocybe novembrina Velenovský, Novitates mycologicae, 71. 1939. - Lectotype (selected here) examined: Czechoslovakia, Mnichovice, in pinetis calidis XI. 1935, J. Velenovský (PR 153396). This specimen, which clearly belongs to the type material, is almost certainly C. phyllophila v. phyllo- phila. The fact that the original description indicates the spores to be globose may be attributed, for example, to poor optics or the occurrence of most of the spores in tetrads.

Clitocybe obscurata Cooke, Trans. British Mycol. Soc. 3: 109. 1909. - Holotype? (England, Cumberland, Carlisle X. 1908, Decima Graham; K) examined. It is difficult to decide whether this sole specimen of the type material is the true holotype. As Dennis (1948) has pointed out, the protologue states that the species was collected in September while the label note gives the month as October. Dennis (op.c.) concluded that the specimen probably belongs to C. clavipes, being perhaps a form of this species. I consider that the collection simply represents C.clavipes, which is one of the Clitocybe species with rather characteristic spores. Cooke stated that his species differed from C.clavipes in having a differently shaped pileus and stipe. Such differences alone, even when genetically determined, do not warrant the separation of this sole collection from C.clavipes, nor would anything be gained by recognizing obscurata as an infraspecific taxon of C.clavipes. In England, specimens of $C$. clavipes with a non-clavate stipe have sometimes been misnamed: I have seen such collections labelled C. subinvoluta and $C$. squamulosoides (see later in the present paper).

Clitocybe olida Velenovský, Opera bot. čechica 4 (Novitates mycologicae novissimae) : 54. 1947. - Holotype? (Czechoslovakia, Mnichovice 29. VII. 1940, J. Velenovský; PR 153481) examined. It is not certain that this specimen is the holotype. Firstly, it was collected at Mnichovice, Všesisny, while according to the protologue C. olida was found in July 1940 near Mnichovice, Božkov. Secondly, Velenovský described the spores as globose, $5-7 \mu \mathrm{m}$ in diameter, and punctate, though these observations may be erroneous. The specimen is C. candicans. It may be noted, too, that the binomial $\gg$ Clitocybe olida» had been used twice earlier, viz. for C. olida Vel. 1920 (no material in PR or PRG) and C. olida (Quél.) Konr. 1929.

Clitocybe praecox Kauffman, The Agaricaceae of Michigan 1: 724. 1918. - Holotype (part) (U.S.A., Michigan, Washtenaw Co., Ann Arbor 25. IV. 1910, C. H. Kauffman; MICH) examined. The collection 
obtained for examination was described as »ex holotype», these words having obviously been written by the herbarium staff before sending this part of the main collection. However, the original description did not give any exact collecting data, the species being reported to have been found between the 20th of April and the first of June. However, it seems very probable that this is a part of the true holotype. The specimen is very probably $C$. sinopica. Some spores are slightly broader (up to ca. $6.5 \mu \mathrm{m}$ ) than is usual in C. sinopica, but the amplitude of variation of the length of the spores is about the same.

Clitocybe rhizoides Bigelow \& Hesler, Journ. Elisha Mitchell Sci. Soc. 76: 161. 1960. - Isotype (U.S.A., Tennessee, Knox Co. 16. I. 1949, L. R. Hesler 18894; H) examined. Prof. Hesler was kind enough to donate a part of the holotype in TENN (= isotype) to the herbarium in Helsinki. This specimen as well as another one sent by him (Hesler \& Bigelow 10153) belong to the characteristic species C. pruinosa (Lasch ex Fr.) Kumm. (=C. radicellata auct.). The morphology and ecology of C. pruinosa have been described in Harmaja 1969. The winter occurrence in coniferous woods in Tennessee and the rather dark pigmentation of the fruit bodies agree exactly with the characters of the N.W. European population. The clear abundance of encrusted crystals in the pileus and lamellae (see Harmaja 1969: 27, 73) is also diagnostic. In $C$. pruinosa and $C$. candicans in particular these crystals cause parts of thickish sections of the pileus and pieces of the lamella to look characteristically pale in Melzer's reagent and other mounts. They bind air bubbles and thus prevent the tissue from getting soaked through with the mounting liquid, unless the cover glass is pressed tightly against the section.

( $I$ have earlier considered these crystals to be some kind of encrusted pigment, but it seems better to think of them as some perhaps useless products of metabolism, resembling the cystidial crystals of Melanoleuca and Inocybe. They are not calcium oxalate because they do not seem to be soluble in dilute hydrochloric acid; nor did dilute sulphuric acid have any effect on them.)

An interesting detail was noted in the collection Hesler \& Bigelow 10153. A young fruit body (also studied microscopically) seemed to be an albino without the dull pigment in the cap and the stipe.

Clitocybe squamulosoides Orton, Trans. British Mycol. Soc. 43: 187. 1960. - Isotype (England, Surrey, Witley Common 13. XII. 1956, P. D. Orton; H) examined. Dr. OrTon kindly presented part of the holotype in $\mathrm{K}$ (= isotype) to the herbarium in Helsinki. The specimen represents C.clavipes with an unusual non-clavate stipe. The other macroscopical and microscopical characters agree with those of $C$. clavipes, which can be recognized on the basis of the spore features alone (see Harmaja 1969). The sweetish odour which has been mentioned by Orton, is typical of C.clavipes, and was probably also noticeable in the isotype specimen.

Clitocybe subconnexa Murrill, Mycologia 7: 272. 1915. - Holotype (U.S.A., New York, New York Botanical Garden 26. IX. 1911, W. A. Murrill; NY) examined. The spores are as follows: $4.7-6.2 \times 3.0-4.0$ $\mu \mathrm{m}$, mostly occurring in tetrads (and dyads) in preparations made of pieces of lamellae, a proportion of them always having shrunken walls without contents, all obtuse-based, all elliptical, hyaline to faintly yellowish in Melzer's reagent, the suprahilar area (plage) \pm applanated (and smooth?), thin-walled, distinctly verruculose (very probably with low, flat or semiorbicular particles, smaller than the apiculus, and without sharp spines), contents indistinctly granulose to homogeneous, apiculus oblique, truncate, equal, ca. $0.6-0.7 \times 0.5-0.6 \mu \mathrm{m}$. These spores show the specimen to belong to the genus Lepista (Fr.) W. G. Smith (in addition, the spore deposit of C. subconnexa is reported by Bigelow \& Sмiтн [1969] to have pinkish buff tints). This is also indicated by the clamp connections. It represents a valid species, which is close to L. luscina, and I therefore propose the following new combination: Lepista subconnexa (Murr.) Harmaja, n. comb. (basionym Clitocybe subconnexa Murrill, Mycologia 7: 272. 1915.). L. subconnexa is characterized by being often cespitose in habit, by the pale white (evidently pruinose) to partly pale brownish pileus, the margin of which remains a very long time narrowly inrolled, the very crowded more or less decurrent lamellae which are yellowish to buff-tinted when dry, the thin and somewhat hard and brittle context of the pileus 
in dry basidiocarps, and the small rough spores, most of which occur in tetrads in gill preparations. A species which I call Lepista luscina (Fr.) Sing. seems to be a near relative. I did not find any distinct differences between the spore characters of $L$. subconnexa and those of L. luscina, but a more thorough study may, of course, reveal such. However, the latter is evidently not cespitose, and is fleshier, dried fruit bodies displaying a thicker and softer context; its colours are rather dull and greytinged; its stipe is shorter, and its gills are not decurrent (perhaps slightly so in old basidiocarps?) being broader, less bright in colour, and more widely spaced. L. subconnexa occurs in Fennoscandia, too, for I have seen specimens of this species, determined as Clitocybe spp., from Norway (Selsmyr 30. VII. 1924, leg. Odd Klykken; O) and Finland (Etelä-Häme, Tammela, near Mustiala 28. IX. 1878 \& 30. VIII. 1903, leg. P. A. Karsten; H). It is evidently the first time that this species is reported from these countries.

Bigelow \& Smith (op.c.) have recently joined the genus Lepista to Clitocybe, treating it as a new section, Verruculosae Big. \& Smith. I have not studied material of the species representing »connecting links» between Clitocybe and Lepista and so far share the opinion of SiNGER and many others that Lepista is a distinct genus. A discussion of the taxonomy of Tricholomataceae would not be in place here (cf. also Harmaja 1969: 10), but I admit that Lepista is very probably closer to Clitocybe than to, for example Tricholoma. Nor do I wish to suggest that the present status (sensu Singer et al.) of Lepista should be considered unalterable.

Lepista caespitosa (Bres.) Sing. may be a synonym of $L$. subconnexa. It was described by Bresadola as a form of Tricholoma panaeolum before MURRILL created his species, but the epithet caespitosa was not used at specific level till after 1915, so it is better to reject the name $L$. caespitosa which is better-known, at least in Europe, and use so far the binomial L. subconnexa instead. My supposement regarding this synonymy is based on a study of the four specimens from northern Italy of $\gg$ Tricholoma paneolum $\mathrm{f}$. (or var.) caespitosa Bres.» in the Bresadola Herbarium (S), which, at least partly represent L. subconnexa. Unfortunately, all of them were collected after 1898, the year of the publication of Bresadola's form. Three of them have been collected by other people than BRESADOLA, and there is no indication about the collector of the fourth. Accordingly, we have no holotype or lectotype, and the neotype should preferably be chosen in connection with a monographic study of Lepista. This synonymy is thus not quite certain. BigeLow \& Smrth (op.c.) considered L. caespitosa a different species from L. subconnexa and transferred it to Clitocybe as a nomen novum, C. fasciculata Big. \& Smith, without, however, having examined any type material of L. caespitosa or the four specimens at Stockholm. C.fasciculata was not provided with a Latin description or a type specimen, so it should evidently be typified with Bresadola's type of T.panaeolum f. caespitosum, which is missing, as stated earlier. As mentioned above, the topotypical material of BRESADoLA's form at least partly represents $L$. subconnexa. It would appear to be best to refrain from using the name $C$. fasciculata. If the North American material cited by BigELow \& SMrTH as representing the last-named species is indeed specifically different from L. subconnexa, C.fasciculata ought to be provided with a Latin diagnosis and a North American type specimen. It should perhaps be mentioned that, while Bigelow \& Smith (op.c.) write that the taste of $C$. fasciculata is very disagreeable, BrEsadola described his new form as tasting mild, and MurRILl said the same of his new species. The odours were described differently by the two last-named authors, but the odour of $L$. subconnexa may vary somewhat. It should be kept in mind, that the same odour may be described differently by two different persons, and that old basidiocarps of many agarics may differ from the young ones in possessing a disagreeable odour.

Clitocybe tenuissima Romagnesi in Kühner \& Romagnesi, Bull. Soc. Nat. d'Oyonnax 8: 74. 1954. - 》Allotypus» (France, near Paris 27. X. 1946, det. [also collected?] H. Romagnesi; PG) examined. I received on loan only a pileus designated as »allotypus». A comparison of the label notes with the protologue does not help in judging whether the specimen is a part of the holotype (= isotype) or not. The specimen is C.candicans. At least till the true holotype with whole carpophores is available for examination, the name C. tenuissima must accordingly be rejected. 
Clitocybe umbrinipes Bigelow \& Smith, Mycologia 54: 514. 1963. - Holotype (part) (U.S.A., Washington, Pierce Co. 1.X. 1954, H. E. Bigelow 2173; MICH) examined. The specimen represents $C$. inornata with its unmistakable spores. C. umbrinipes was described on the basis of the type collection only. Even by itself the original description strongly suggests $C$. inornata. The species was said to differ from C.inornata in having broader gills and a paler and broadly infundibuliform adult pileus, while the young carpophores of these two species were thought to be virtually indistinguishable. According to my experience, the above differences, even if genetically determined, are not enough to justify separation at specific level in Clitocybe, where the form of the pileus may vary widely in some species as well as various macroscopical features of the lamellae (also in C.inornata). It is remarkable that C. umbrinipes was described from one collection only, where the slight macroscopical differences may easily be thought to lie within the normal amplitude of variation of the respective characters of C. inornata.

Clitocybe washingtonensis Murrill, Mycologia 5: 214. 1913. - Holotype (U.S.A., Washington, Seattle 20.X.-1.XI.1911, W. A. Murrill 615a; NY) examined. The type specimen is in very poor condition, but it can still be seen that the fruit bodies are of moderate size, the pileus whitish with an involute white margin, and the lamellae yello- wish. Clamp connections are abundant. The spores are small, mostly elliptical, and most of them occur in tetrads in Melzer squash preparations made from a piece of lamella. The protologue agrees with those characters which can still be observed, except the spore size, as the spores were stated to measure $7-8 \times 3-4 \mu \mathrm{m}$, which would indicate larger spores than in C. phyllophila. The specimen has, however, quite evidently been stamped as the type by Murrill. He stated his species to be nearly related to C.cerussata. I could not find any differences between the sporal and other characters of C. washingtonensis and those of C.phyllophila v. phyllophila. I therefore consider it very probable that C.washingtonensis is a synonym of $C$. phyllophila v. phyllophila (this species has often been called C.cerussata, but this name must be rejected; see Harmaja 1969: 87).

Omphalina jalapensis Murrill, North American Flora 9: 349. 1916. - Holotype (Mexico, Vera Cruz, Jalapa, at an altitude of 5000 ft., 12.-20. XII. 1909, W. A. Murrill 165 \& Edna L. Murrill; NY) examined. The specimen with a deeply infundibuliform pileus is a beautiful representative of Clitocybe hydrogramma with its characteristic spores and, above all, its peculiar epicutis. Bigelow (1970) came to the same conclusion. C. adirondackensis (Peck) Sacc., a much used name in North America is evidently another synonym of C. hydrogramma.

\section{REFERENCES}

Brgelow, H. E. 1968: The genus Clitocybe in North America. II. Section Infundibuliformes. - Lloydia 31: 43-62.

- 1970: Omphalina in North America. Mycologia 62: 1-32.

- and Smith, A. H. 1969: The status of Lepista - a new section of Clitocybe. Brittonia 21: 144-177.

Dennis, R. W. G. 1948: Some little-known British species of Agaricaceae. I. Leucosporae and Rhodosporae. - Trans. British Mycol. Soc. 31: 191-209.

Harmaja, H. 1969: The genus Clitocybe (Agaricales) in Fennoscandia. - Karstenia 10: $5-168$.

Singer, R. 1942: Type studies on Agarics. Lloydia 5: $97-135$. 